Article

\title{
Impact of the 2016 Policy Change on the Delivery of MedsCheck Services in Ontario: An Interrupted Time-Series Analysis
}

\author{
Ahmad Shakeri ${ }^{1}$, Lisa Dolovich ${ }^{1,2,3}$, Lori MacCallum ${ }^{1,4}$, John-Michael Gamble ${ }^{2}$, Limei Zhou ${ }^{5}$ \\ and Suzanne M. Cadarette $1,5,6,7, *$ (D) \\ 1 Leslie Dan Faculty of Pharmacy, University of Toronto, Toronto, ON M5S 3M2, Canada \\ 2 School of Pharmacy, University of Waterloo, Kitchener, ON N2L 3G1, Canada \\ 3 Department of Family Medicine, McMaster University, Hamilton, ON L8P 1H6, Canada \\ 4 Banting \& Best Diabetes Centre, Faculty of Medicine, University of Toronto, Toronto, ON M5G 2C4, Canada \\ 5 ICES, Toronto, ON M5T 3M6, Canada \\ Dalla Lana School of Public Health, University of Toronto, Toronto, ON M5T 3M7, Canada \\ 7 Eshelman School of Pharmacy, University of North Carolina, Chapel Hill, NC 27599-7355, USA \\ * Correspondence: s.cadarette@utoronto.ca; Tel.: +1-416-978-2993
}

Received: 1 June 2019; Accepted: 6 August 2019; Published: 12 August 2019

\begin{abstract}
MedsCheck (MC) is an annual medication review service delivered by community pharmacists and funded by the government of Ontario since 2007 for residents taking three or more medications for chronic conditions. In 2010, MC was expanded to include patients with diabetes (MCD), home-bound patients (MCH), and residents of long-term care homes (MCLTC). The Ontario government introduced an abrupt policy change effective 1 October 2016 that added several components to all MC services, especially those completed in the community. We used an interrupted time series design to examine the impact of the policy change ( 24 months pre- and post-intervention) on the monthly number of MedsCheck services delivered. Immediate declines in all services were identified, especially in the community $(47 \%-64 \%$ drop MC, $71 \%-83 \%$ drop $\mathrm{MCD}, 55 \%$ drop $\mathrm{MCH}$, and $9 \%-14 \%$ drop MCLTC). Gradual increases were seen over 24 months post-policy change, yet remained $21 \%-76 \%$ lower than predicted for MedsCheck services delivered in the community, especially for MCD. In contrast, MCLTC services were similar or exceeded predicted values by September 2018 (from 5.1\% decrease to 3.5\% increase). A more effective implementation of health policy changes is needed to ensure the feasibility and sustainability of professional community pharmacy services.
\end{abstract}

Keywords: community pharmacy services; health policy; interrupted time series analysis; medication reconciliation

\section{Introduction}

Chronic medications are often critical to an individual's ability to maintain and improve their health [1]. However, drug therapy problems, such as unnecessary therapy, ineffective dosage, and adverse drug reactions are common [2,3]. Effective strategies to identify and decrease drug therapy problems are important to reduce the potential harms from medication [4]. Community pharmacists are widely accessible and commonly maintain a comprehensive record of an individual's prescription medications [5]. Community pharmacists are thus well positioned to effectively identify drug therapy problems and prevent adverse drug events [6,7]. Community-pharmacist medication review programs are well-established and publicly funded in Australia, Denmark and the United Kingdom [8-10]. Canada has universal Medicare that covers all medically necessary physician services, and at minimum, 
partial coverage of medications listed on provincial formularies for seniors and specialized vulnerable groups [11]. In April 2007, the government of Ontario launched the MedsCheck program as the first publicly funded community-pharmacy delivered professional service outside of drug dispensation. When it was originally introduced, the MedsCheck (MC) service was a one-on-one annual consultation service in a community pharmacy that provided education and assessed adherence to therapy. The program targeted Ontario residents taking three or more medications for chronic conditions, and pharmacy reimbursement was limited to once every 12 months [12]. The opportunity for pharmacies to be reimbursed for unlimited follow-up services was added in November 2007. In September 2010, the MedsCheck program was expanded to include people with diabetes (MCD), people unable to physically attend a medication review service in a pharmacy due to physical or mental incapability (MedsCheck at Home $[\mathrm{MCH}]$ ), and residents in long-term care (MCLTC) $[13,14]$. In addition, unlimited follow-up services within the year were included for MCD and quarterly services were included for MCLTC. MC and MCD annuals and their respective follow-ups are completed in community pharmacies, whereas $\mathrm{MCH}$ and MCLTC occur in a person's place of residence. Pharmacies are reimbursed for these services by submitting a claim to the Ontario Drug Benefit program. Of interest is the fact that all long-term care (LTC) homes are required by legislation to ensure pharmacist participation in quarterly and annual medication reviews with each patient [13].

The Ontario government announced changes to MedsCheck service delivery in July 2016 that were implemented on 1 October 2016. The mandatory changes added several components to each service, including follow-up services, such as requiring written patient consent, structured pharmacist documentation, and the provision of summary information and recommendations to physicians (Table 1) [15]. MCD included an extra set of assessment parameters related to diabetes education and goal-setting, and new requirements that pharmacists have either a certified diabetes educator designation or have gained adequate diabetes management knowledge through a professional continuing education program approved by the Canadian Council on Continuing Education in Pharmacy [13,16]. However, MCD follow-up services were less rigorous, intended for education and did not require a complete medication review. The objective of this study was to estimate the change in the monthly number of MedsCheck services delivered following the 2016 policy change.

We hypothesized that the increased workload accompanying the policy change and added documentation and training requirements for MCD delivery would impact the feasibility of community services, and thus, an immediate decline in the number of services would be identified. However, given that regular medication reviews are required in LTC, we hypothesized that pharmacies would leverage the MCLTC program to meet medication review requirements and thus, changes to the program would have minimal impact on the frequency of MCLTC services.

\section{Materials and Methods}

\subsection{Study Design}

We used an interrupted time-series segmented regression design to study trends in the monthly services delivered [17-19]. Interrupted time series is a robust, quasi-experimental approach for evaluating the effects of policy and public health interventions $[17,20]$. This method models changes in the level (immediate impact) and trend (slope) after a policy change; in our case, we examined the change in monthly MedsCheck services following the 1 October 2016 policy change. 
Table 1. MedsCheck documentation requirement pre- and post-October 2016 policy change.

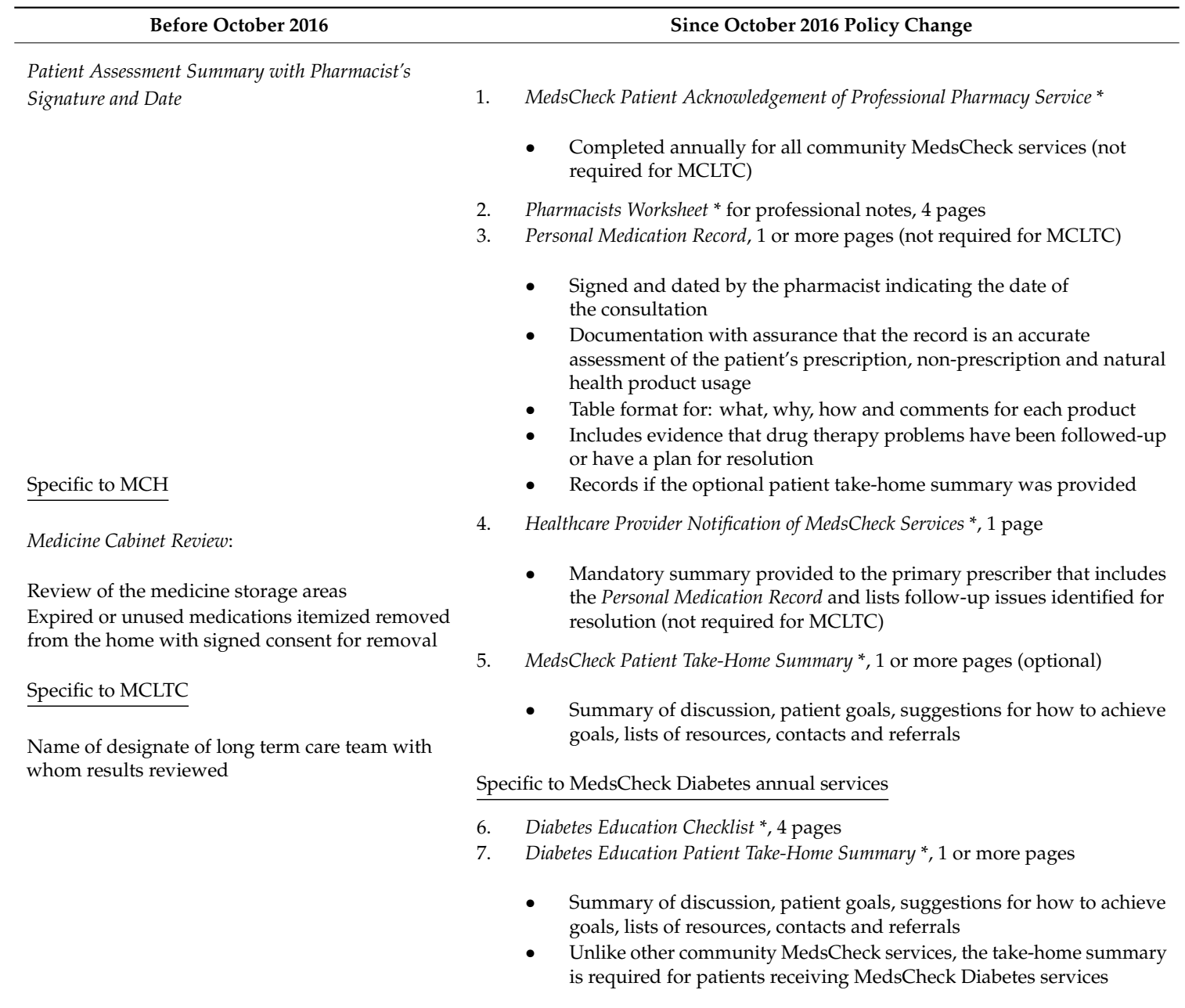

\footnotetext{
* Standardized forms, available at http://www.forms.ssb.gov.on.ca/, accessed on 2 May 2019 [15]; MCH: MedsCheck at Home, MCLTC: MedsCheck Long-Term Care.
}

\subsection{Data Sources}

We identified all MedsCheck services from October 2014 to September 2018 based on the product identification number submitted to the Ontario Drug Benefit program (Table 2). Age and sex were identified from the Registered Persons Database. These data were linked using unique encoded identifiers and analyzed at ICES. Records with errors (death date prior to first service date, age $<0$, missing age or missing sex) were excluded, and duplicate claims in the same month were deleted. The total number of claims over the study period and the proportion of women and mean age of people receiving each service were summarized by MedsCheck type (MC, MCD, MCH or MCLTC) based on their first service date of each type. 
Table 2. MedsCheck service administrative codes and reimbursement fees as of October 2016.

\begin{tabular}{|c|c|c|}
\hline Service & PIN & Fee \\
\hline \multicolumn{3}{|c|}{ MedsCheck (MC) ${ }^{1}$} \\
\hline MC annual & 93899979 & $\$ 60^{1}$ \\
\hline \multicolumn{3}{|l|}{ MC follow-up } \\
\hline - Hospital discharge $\leq 2$ weeks & 93899981 & \\
\hline - Pharmacist decision & 93899982 & $\$ 25$ \\
\hline - Physician or nurse practitioner referral & 93899983 & \\
\hline - Planned hospital admission & 93899984 & \\
\hline \multicolumn{3}{|c|}{ MedsCheck Diabetes (MCD) ${ }^{2}$} \\
\hline MCD annual & 93899988 & $\$ 75$ \\
\hline MCD follow-up & 93899989 & $\$ 25$ \\
\hline \multicolumn{3}{|c|}{ MedsCheck at Home (MCH) ${ }^{3}$} \\
\hline $\mathrm{MCH}$ annual & 93899987 & $\$ 150$ \\
\hline \multicolumn{3}{|c|}{ MedsCheck Long Term Care (MCLTC) ${ }^{4}$} \\
\hline MCLTC annual & 93899985 & $\$ 90$ \\
\hline MCLTC quarterly & 93899986 & $\$ 50$ \\
\hline
\end{tabular}

1 \$50 before October 2016, eligible for residents with valid Ontario health card taking 3 or more chronic medications. ${ }^{2}$ eligible for residents with diabetes and a valid Ontario health card. ${ }^{3}$ eligible for residents with a valid Ontario health card and with diabetes or taking 3 or more chronic medications and unable to attend community pharmacy to have a MedsCheck service. ${ }^{4}$ eligible for residents of licensed long-term care (LTC) homes with valid Ontario health card and taking 3 or more chronic medications. Pharmacist participation in annual and quarterly medication review services in LTC are required by legislation [13]. PIN: Product Identification Number.

\subsection{Analytical Approach}

The primary outcome was the monthly number of MedsCheck claims by MedsCheck service type (MC annual or follow-up, MCD annual or follow-up, MCH, MCLTC annual or quarterly). We used segmented regression to study trends in monthly service delivery, accounting for autocorrelation, non-stationarity and seasonality. Autocorrelation was examined in the data using the Durbin-Watson test [21] and autocorrelation plots, and stationarity was tested using the Dickey-Fuller test [22]. We specified our model to estimate level and trend changes in MedsCheck services in the 24-months pre-implementation and 24-months post-implementation periods, while accounting for seasonality, non-stationarity, and autocorrelation.

$$
y=\beta_{0}+\beta_{1} \times \text { time }+\beta_{2} \times \text { implementation }+\beta_{3} \times \text { time after }+e
$$

Equation (1) Generalized equation (autoregressive and moving average terms not included).

Equation (1) includes the generalized equation, where y was the number of MedsCheck services delivered, $\beta_{0}$ the number of MedsCheck services delivered in October 2014, $\beta 1$ the monthly trend in MedsCheck service delivery pre-implementation (October 2014-September 2016), $\beta 2$ the immediate (level) change in monthly MedsCheck services after implementation (October 2016), $\beta 3$ monthly trend in MedsCheck service delivery post-implementation (October 2016-September 2018), and $e$ the random error. The pre-intervention level and linear trends were plotted using model coefficients, and the level and trend predicted values absent of the policy change were calculated for comparisons [23]. Analyses were completed using R 3.5.2 (Vienna, Austria) leveraging the Companion to Applied Regression (car) and Linear and Nonlinear Mixed Effects Models (nlme) packages [24].

\section{Results}

We identified 2,952,434 MC annual or follow-up services, 848,911 MCD annual or follow-up services, 103,591 MCH services, and 1,084,410 MCLTC annual or quarterly services over the 48-month study period, Table 3. The mean age at the first Medscheck service was lowest for MC (mean $=58.3$, 
$\mathrm{SD}=17.3$ ) and highest for MCLTC (mean $=82.6, \mathrm{SD}=10.5)$. Besides MCD, a higher proportion of MedsCheck service recipients were women.

Table 3. Demographic information of recipients and total number of Medscheck claims, by service type *.

\begin{tabular}{ccccc}
\hline Service Type & $\begin{array}{c}\text { MedsCheck } \\
\text { (Annual or } \\
\text { Follow-Up) }\end{array}$ & $\begin{array}{c}\text { MedsCheck } \\
\text { Diabetes (Annual } \\
\text { or Follow-Up) }\end{array}$ & $\begin{array}{c}\text { MedsCheck at } \\
\text { Home }\end{array}$ & $\begin{array}{c}\text { MedsCheck Long } \\
\text { Term Care (Annual or } \\
\text { Quarterly) }\end{array}$ \\
\hline Number of recipients & 647,740 & 209,060 & 57,583 & 95,191 \\
Number of Service claims & $2,952,434$ & 848,911 & 103,591 & $1,084,410$ \\
Age, mean (SD) & $58.3(17.3)$ & $60.6(14.2)$ & $74.4(16.4)$ & $82.6(10.5)$ \\
Women, \% & 52.4 & 45.2 & 62.1 & 64.0 \\
\hline
\end{tabular}

* Age and sex for each service type based on first service date for that service type. SD = Standard Deviation.

In the two years pre-intervention, there was a significant monthly increase for MCD annual and $\mathrm{MCH}$; yet, we observed a slight significant monthly decline for MCLTC annual (Table 4). A significant immediate and large drop in the monthly number of MedsCheck community services was seen after policy implementation (October 2016), ranging from $47 \%$ to $64 \%$ for MC (Figure 1), $71 \%$ to $83 \%$ for MCD (Figure 2), and was 55\% for MCH (Figure 3). In contrast, a considerable smaller decline was seen for MCLTC, ranging from 9\% to 14\% (Figure 4). Gradual increases were seen over 24 months post-intervention period, yet remained $21 \%$ to $76 \%$ lower than predicted for MedsCheck services delivered in the community, particularly for MCD. In contrast, MCLTC services were similar to or exceeded predicted values by September 2018 (from a 5.1\% decrease to a 3.5\% increase). 
Table 4. Results of interrupted time-series segmented regression models, October 2014-September 2018, with intervention (policy change) 1 October 2016.

\begin{tabular}{|c|c|c|c|c|c|c|c|}
\hline \multirow[b]{2}{*}{ Parameter } & \multicolumn{2}{|c|}{ MedsCheck } & \multicolumn{2}{|c|}{ MedsCheck Diabetes } & \multirow{2}{*}{$\begin{array}{l}\text { MedsCheck at } \\
\text { Home }\end{array}$} & \multicolumn{2}{|c|}{ MedsCheck Long Term Care } \\
\hline & Annual & Follow-Up & Annual & Follow-Up & & Annual & Quarterly \\
\hline Total Claims & $2,356,615$ & 595,819 & 664,483 & 184,428 & 103,591 & 285,403 & 799,007 \\
\hline $\begin{array}{l}\text { Monthly Claims } \\
\text { - Minimum number } \\
\text { - Maximum number }\end{array}$ & $\begin{array}{l}22,973 \\
70,554\end{array}$ & $\begin{array}{c}5768 \\
21,353\end{array}$ & $\begin{array}{c}4314 \\
23,443\end{array}$ & $\begin{array}{c}896 \\
8304\end{array}$ & $\begin{array}{l}1151 \\
3482\end{array}$ & $\begin{array}{l}4493 \\
7074\end{array}$ & $\begin{array}{l}14,000 \\
18,687\end{array}$ \\
\hline \multicolumn{8}{|c|}{ Results of Segmented Regression Models } \\
\hline Baseline (October 2014), number (95\% CI) & $\begin{array}{c}63,223 \\
(60,452,65,994)\end{array}$ & $\begin{array}{c}16,698 \\
(15,826,17,771)\end{array}$ & $\begin{array}{c}18,984 \\
(18,069,19,899)\end{array}$ & $\begin{array}{c}6704 \\
(6157,7251)\end{array}$ & $\begin{array}{c}2575 \\
(2454,2697)\end{array}$ & $\begin{array}{c}6274 \\
(6199,6349)\end{array}$ & $\begin{array}{c}16,848 \\
(16,355,17,341)\end{array}$ \\
\hline $\begin{array}{l}\text { Pre-intervention slope, mean monthly claims } \\
(95 \% \mathrm{CI})\end{array}$ & $\begin{array}{c}-173 \\
(-373,27)\end{array}$ & $\begin{array}{c}67 \\
(-1,135)\end{array}$ & $\begin{array}{c}81 \\
(14,149) \\
\end{array}$ & $\begin{array}{c}-19 \\
(-57,19)\end{array}$ & $\begin{array}{c}15 \\
(6,24)\end{array}$ & $\begin{array}{c}-6 \\
(-11,-0.3)\end{array}$ & $\begin{array}{c}18 \\
(-17,52)\end{array}$ \\
\hline $\begin{array}{l}\text { Level Change at Intervention (October 2016) } \\
\text { - Number of claims }(95 \% \mathrm{CI}) \\
\text { - Relative percent change }(95 \% \mathrm{CI})\end{array}$ & $\begin{array}{c}-28,167 \\
(-32,034,-24,302) \\
-46.7 \\
(-52.9,-40.4) \\
\end{array}$ & $\begin{array}{c}-11,854 \\
(-13,205,-10,503) \\
-64.3 \\
(-71.1,-57.3) \\
\end{array}$ & $\begin{array}{c}-14,876 \\
(-16,244,-13,508) \\
-70.5 \\
(-76.7,-64.3) \\
\end{array}$ & $\begin{array}{c}-5214 \\
(-5942,-4487) \\
-83.2 \\
(-94.3,-72.1) \\
\end{array}$ & $\begin{array}{c}-1635 \\
(-1828,-1442) \\
-55.0 \\
(-61.2,-48.8) \\
\end{array}$ & $\begin{array}{c}-929 \\
(-1034,-825) \\
-14.4 \\
(-16.0,-12.8) \\
\end{array}$ & $\begin{array}{c}-1656 \\
(-2348,-965) \\
-9.4 \\
(-13.2,-5.6) \\
\end{array}$ \\
\hline $\begin{array}{l}\text { Post-intervention slope, mean monthly } \\
\text { claims }(95 \% \mathrm{CI})\end{array}$ & $\begin{array}{c}521 \\
(42,1002)\end{array}$ & $\begin{array}{c}52 \\
(-110,215)\end{array}$ & $\begin{array}{c}139 \\
(-17,296)\end{array}$ & $\begin{array}{c}16 \\
(-77,108)\end{array}$ & $\begin{array}{c}22 \\
(4,40)\end{array}$ & $\begin{array}{c}42 \\
(30,54)\end{array}$ & $\begin{array}{c}50 \\
(-33,132)\end{array}$ \\
\hline $\begin{array}{l}\text { Relative difference to forecast (September } \\
\text { 2018), proportion }(95 \% \mathrm{CI})\end{array}$ & $\begin{array}{c}-21.0 \\
(-27.7,-14.3)\end{array}$ & $\begin{array}{c}-61.0 \\
(-67.3,-54.5)\end{array}$ & $\begin{array}{c}-58.9 \\
(-64.6,-53.2)\end{array}$ & $\begin{array}{c}-75.8 \\
(-87.7,-63.8)\end{array}$ & $\begin{array}{c}-44.9 \\
(-50.4,-39.3)\end{array}$ & $\begin{array}{c}3.5 \\
(1.8,5.1)\end{array}$ & $\begin{array}{c}-5.1 \\
(-8.8,-1.3)\end{array}$ \\
\hline
\end{tabular}

CI: Confidence Interval. 


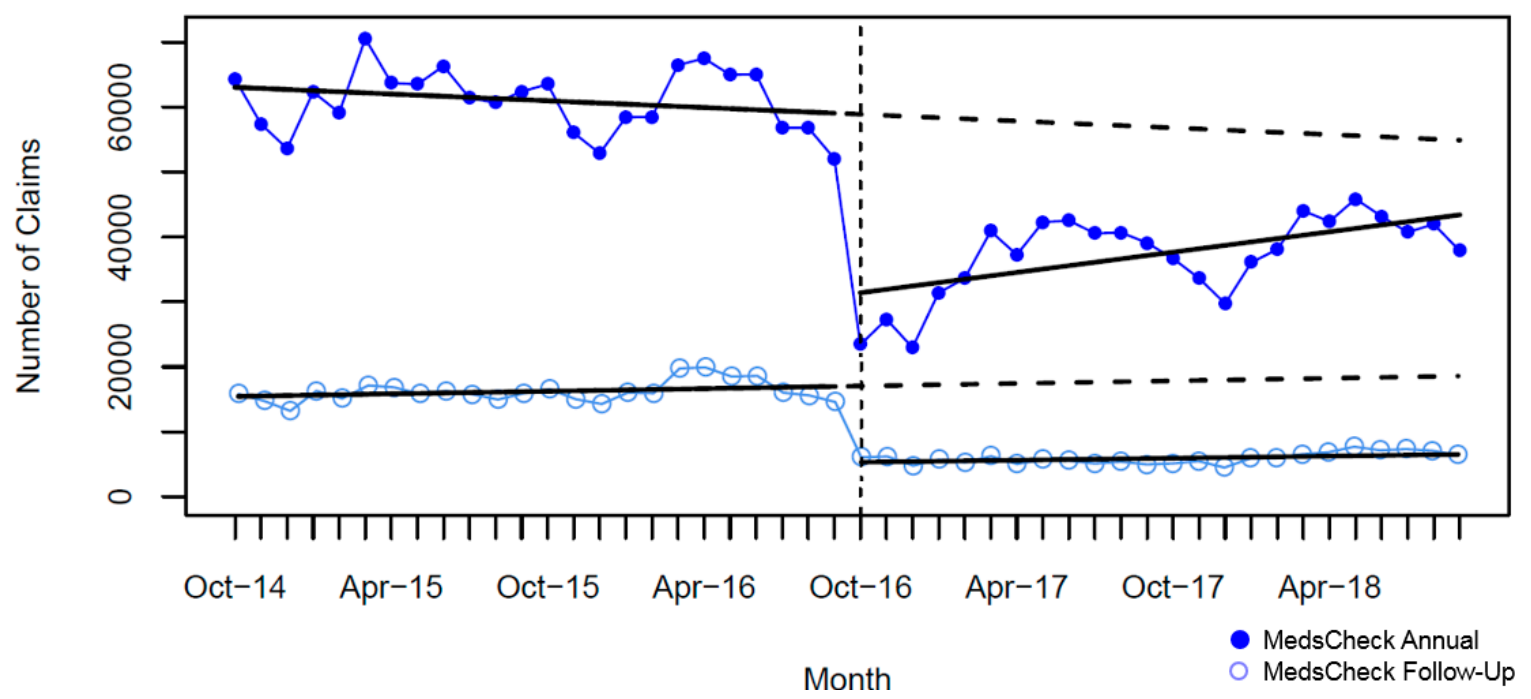

Figure 1. Monthly number of MedsCheck claims relative to the implementation of the October 2016 policy change (vertical dashed line = intervention date). The solid lines show fitted values from the interrupted time series model and the dashed lines show the predicted trend absent the policy change.

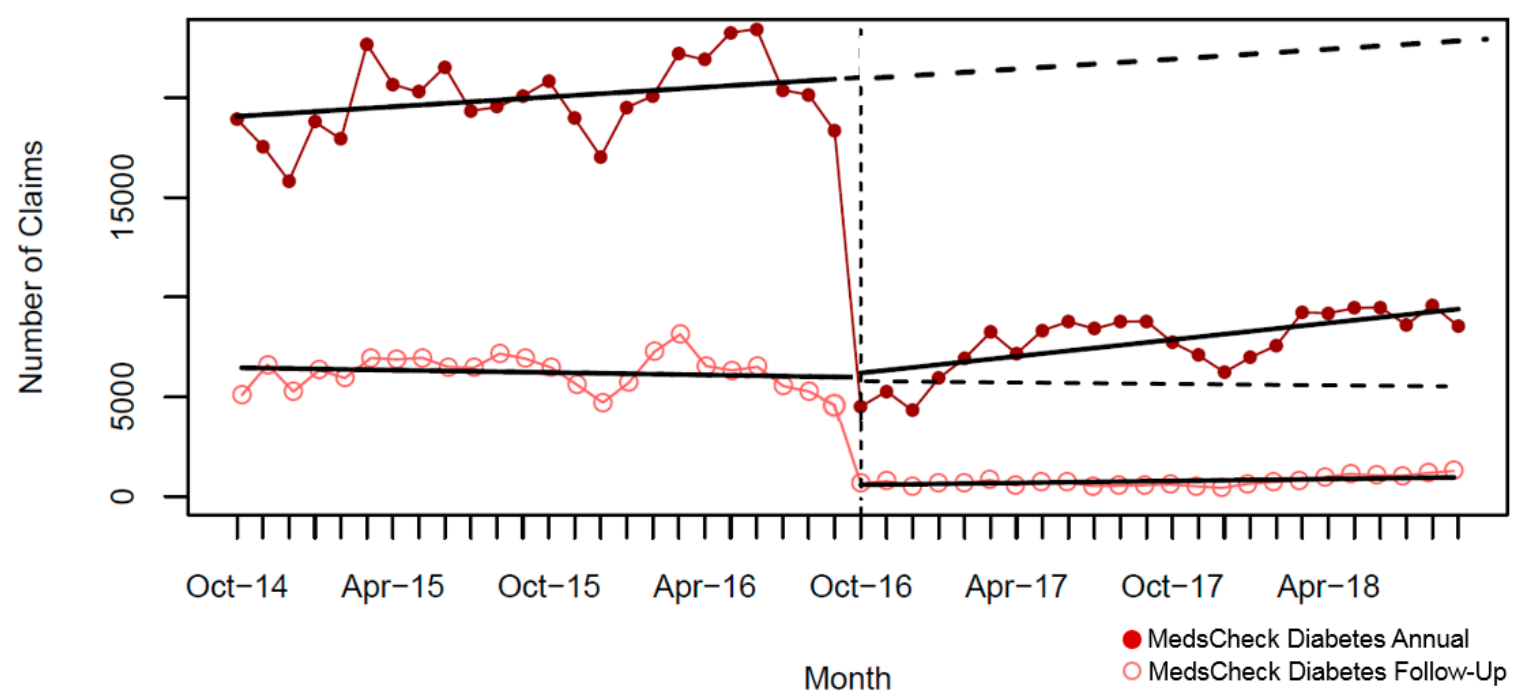

Figure 2. Monthly number of MedsCheck Diabetes claims relative to the implementation of the October 2016 policy change (vertical dashed line $=$ intervention date). Solid lines show fitted values from the interrupted time series model, and dashed lines show the predicted trend absent the policy change. 


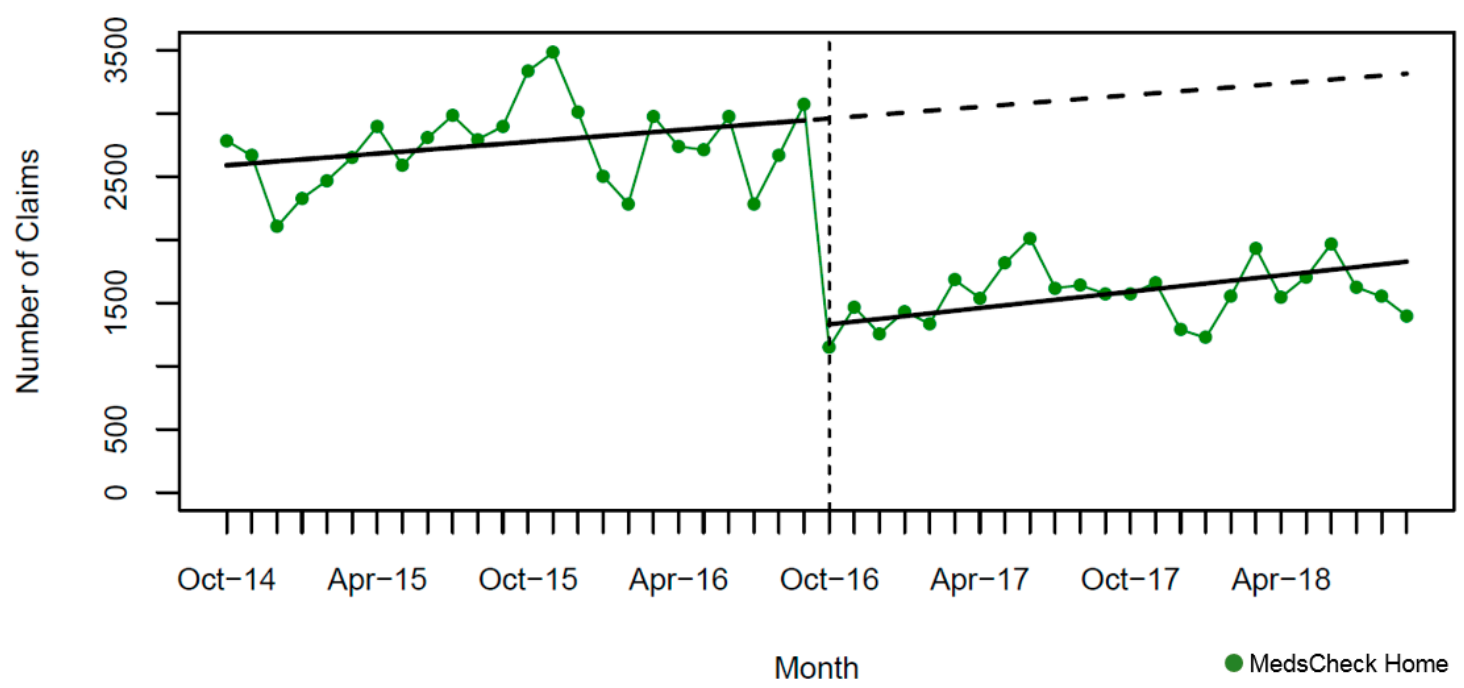

Figure 3. Monthly number of MedsCheck at Home claims relative to the implementation of the October 2016 policy change (vertical dashed line = intervention date). The solid lines show fitted values from the interrupted time series model and the dashed lines show the predicted trend absent the policy change.

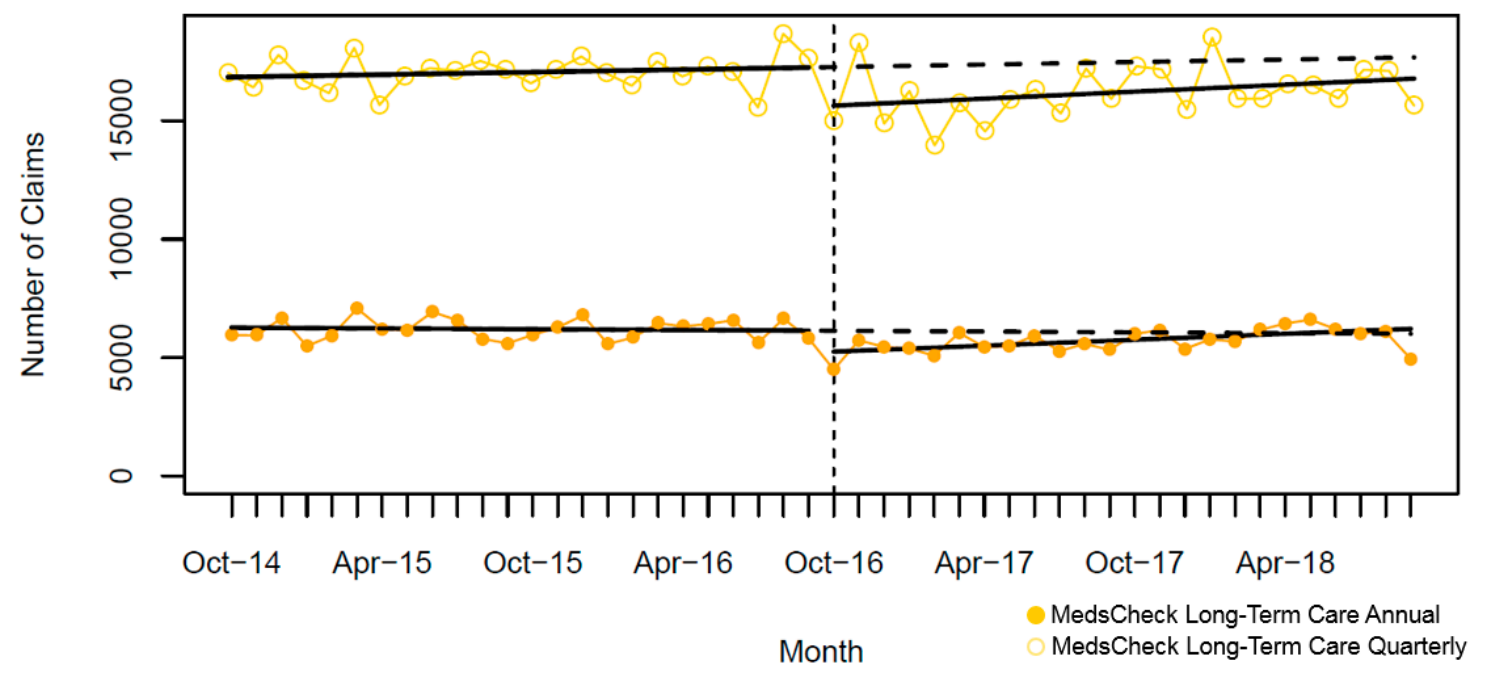

Figure 4. Monthly number of MedsCheck Long Term Care claims relative to the implementation of the October 2016 policy change (vertical dashed line = intervention date). The solid lines show fitted values from the interrupted time series model and the dashed lines show the predicted trend absent the policy change.

\section{Discussion}

MedsCheck was introduced in 2007 as a publicly funded medication review service for patients in the community taking multiple medications, and expanded in 2010 to target other high-risk groups (people with diabetes, home bound and residents of LTC homes) [12,13]. Despite the rapid uptake of these services $[14,25]$, some concerns were raised about quality resulting from the lack of standard documentation or interprofessional coordination [26,27]. In response, the Ontario government consulted the Pharmacy Council-a body that includes representation from the Ontario Pharmacists Association and other stakeholders to provide advice and recommendations related to the pharmacy profession on the development of standardized documentation for the suite of MedsCheck services [28-30]. The added service components resulted in an immediate decline in the number of MedsCheck services delivered in the community. The decreases were generally sustained over the subsequent 2 years. However, there was minimal impact on the number of MedsCheck services 
delivered in LTC. Conceivably, the new requirements may have improved service quality. Future mixed method studies that consider the relative quantity and quality of MedsCheck services pre- and post-policy change are of high interest.

We found that MedsCheck follow-up services remained 61\% (MC follow-up) to 76\% (MCD follow-up) below predicted 24 months after the policy change. This may partially be attributed to pharmacies being ill-equipped to integrate routine follow-up services into their day-to-day workflow. Reminder systems to identify patients that may benefit from follow-up services are not routine. In addition, the use of part-time staffing and recent pharmacy funding cuts [31-34] may make it difficult for pharmacists to step away from their dispensing duties and reach out to patients to conduct a follow-up service [35]. Appointment-based pharmacy models are becoming more common in the United States and research demonstrates that appointment-based models improve the number of prescription fills, reduce the number of trips to the pharmacy, improve vaccination rates, and increase the proportion of patients adherent to therapy [36]. The significant impact of the policy change on the number of follow-up services in our study is concerning since monitoring and follow-up with patients on a consistent basis allows for the evaluation of drug therapy effectiveness and adherence, as well as identifying new drug therapy problems $[37,38]$.

The impact on $\mathrm{MCH}$ is unexpected given the higher reimbursement ( $\$ 150 \mathrm{MCH}$ vs. $\$ 60 \mathrm{MC}$ annual and $\$ 75 \mathrm{MCD}$ annual). However, increased documentation and reporting on top of travel time and expense (i.e., fuel and parking) to visit a patient's home, medicine cabinet reviews and the removal of unused drugs for proper disposal at the pharmacy [39], may have made the service less feasible. $\mathrm{MCH}$ serves an important role in the community as it provides medication review to homebound individuals, typically frail and elderly or living in isolated settings. These patients are often more vulnerable to medication related errors [32]. Managing medications in the home setting is a unique challenge and $\mathrm{MCH}$ has the potential to educate patients and their families about medication therapy, and thus ultimately contribute to improved health and quality of life.

Of interest is the fact that the number of monthly MCLTC services changed minimally after the policy change and by 24 months after the policy change, services were above or close to the predicted values. The legislative requirement for annual and quarterly medication reviews together with existing infrastructure logically made MCLTC more feasible, i.e., much of the labour required in the community was already automated in LTC. MCLTC serves an important role since seniors make up about $12 \%$ of the Canadian population and $2.6 \%$ of all Canadian seniors reside in LTC [40].

Our study had a major strength by leveraging complete population-based level data submitted for reimbursement. However, we were limited in the ability to adjust monthly claims by the number of people eligible to receive MedsCheck services. Drug dispensation for chronic medication is increasing in Ontario [33], therefore, we expect the number of eligible patients for $\mathrm{MC}$ and $\mathrm{MCH}$ services to be increasing over time [41-43]. Similarly, the dispensation of diabetes medications is increasing, indicating an increase in the number of patients eligible to receive MCD services. Finally, the number of LTC beds increased by $2.5 \%$, from 76,982 in 2016 to 78,872 in 2018 [40,44], thus, it is not surprising that we found a 3.5\% higher than projected number of MCLTC annual services by September 2018 . Despite our inability to adjust claims based on the number of eligible claimants, our results are population-based and compelling given the negligible to slow increase in the number of MedsCheck services over time.

Overall, the 2016 policy change that added several documentation and reporting requirements for MedsCheck services was well-intended to help standardize service delivery yet was followed by a substantive decline in the use of MedsCheck services. Although better standardization in program delivery is desirable, better understanding and pilot testing for feasibility before rolling-out new policies is encouraged. Indeed, leveraging a framework to optimize the design and implementation of new programs has the potential to improve success, value and impact $[45,46]$. On 25 April 2019, the Ontario Government announced a proposal to "modernize" the MedsCheck program with a sole focus on transitions in care and LTC [47]. The proposed change will lead to the discontinuation of all 
community MedsCheck services outside of transitions in care. The details have yet to be announced, yet we speculate that the termination of community-based MedsCheck programs relates to the keen interest by the new government to reduce the deficit, coupled with the decline in service delivery and lack of evidence of clinical benefit [48]. For example, the provincial budget notes that "Changing the way pharmacy fees are paid, including a tiered framework for drug mark-up fees; fees paid for filling prescriptions for long-term care home residents, and focusing the MedsCheck program on patients transitioning between health care settings, [will result] in annual savings of over $\$ 140$ million by 2021-22" [49]. The decision to continue supporting MedsCheck services around transitions in care may relate to evidence that supports the benefit of pharmacy-led medication review in reducing readmission rates among patients discharged from hospital [6,49-51].

The impact of the cuts to MedsCheck services on the quality of the Ontario healthcare system is in question, particularly related to the identification and resolution of drug therapy problems. A better understanding of the impact of changes in service delivery on different subgroups of patients is important. At minimum, we identified that patients with diabetes were possibly more impacted by the policy-change with proportionally fewer MCD completed post-policy changes compared to MCH or MC annual. However, it is also possible that pharmacies strategically switched from billing for MCD annual to billing for MC annual among patients with diabetes taking three or more medications to reduce some of the added paperwork specific to MCD. Further exploration of the use of MedsCheck services among patients with diabetes is of interest. Community pharmacists are increasingly involved in patient care through the conduct of regular medication review [52]. In particular, studies from Australia, Canada, the United Kingdom, and the United States show that diabetes education and support delivered through community pharmacies improves care and outcomes [53-55]. However, direct clinical evidence of the various types of medication review programs is scarce. There is a need for well-designed, rigorous studies with more sensitive and specific outcomes that consider the effect of community pharmacists' contributions to reviewing medications on improving health $[52,56,57]$. Our results provide compelling evidence of the immediate and sustained effects of policy decisions on the level of publicly reimbursed professional community pharmacy-delivered services. In the future, policy makers are encouraged to work closely with healthcare providers and fund research to provide evidence of the best mechanisms for the implementation of new pharmacy services $[45,46]$. Funding research to consider the benefits and harms of programs is also important instead of abruptly cancelling programs without considering how to better focus program delivery efforts.

Our research was limited in its ability to understand why the policy change had such a dramatic impact on the number of services delivered, or if the changes impacted the quality of service delivery. Future mixed-methods research is encouraged. Focus groups with community pharmacists will provide a deeper understanding of the experience of delivering MedsCheck services pre- and post-2016 policy change, and thus help uncover the reasoning behind reduced levels of service delivery. Survey research of MedsCheck program recipients may help to clarify the impact of changes on the quality of service delivery, as well as patient satisfaction and possible concerns about the decision by the Ontario government to cancel community services outside transitions in care. Finally, semi-structured interviews with policy decision makers and Pharmacy Council may help clarify the rationale behind the 2016 policy changes, as well as more recent changes to pharmacy practice in Ontario.

\section{Conclusions}

The Ontario government instituted a policy change October 2016 that abruptly changed reporting and documentation requirements that was followed by a sharp and sustained decline in community pharmacy MedsCheck services. Our findings highlight the importance of a well-executed implementation strategy for health policy changes to ensure the feasibility and sustainability of professional community pharmacy services. Despite consulting with pharmacy stakeholders through a formal Pharmacy Council to develop a more standardized service, the comprehensive documentation and interprofessional communication processes put in place were associated with a substantial 
reduction in the number of professional services delivered. The immediate and profound reduction in service delivery speak to the importance and benefits of pilot studies that consider program feasibility in a real-world setting. Better understanding of the impacts of the 2016 policy change on the quality of MedsCheck services and outcomes, as well as potential harms from cancelling many of these services, are needed to inform future policy-decision making.

Author Contributions: Conceptualization, S.M.C.; data curation, L.Z. and S.M.C.; formal analysis, A.S.; funding acquisition, S.M.C. and L.D.; writing-original draft preparation, A.S. and S.M.C.; methodology, A.S., J.-M.G., L.D., S.M.C.; writing-review and editing, J.-M.G., L.D., L.M.C., L.Z. and S.M.C.; supervision, S.M.C.; project administration, S.M.C.

Funding: This research was funded by the Ontario Pharmacy Evidence Network (OPEN) grant from the Government of Ontario to S.M.C. A.S. is supported in part by the Leslie Dan Faculty of Pharmacy Dean's Fund. This study was supported by ICES, which is funded by an annual grant from the Ontario Ministry of Health and Long-Term Care (MOHLTC). The opinions, results and conclusions reported in this paper are those of the authors and are independent from the funding sources. No endorsement by ICES or the Ontario MOHLTC is intended or should be inferred. All analyses were completed at the ICES University of Toronto site, supported by the Leslie Dan Faculty of Pharmacy.

Acknowledgments: The authors thank Avery Loi and Qihang (Abby) Gan who completed undergraduate research project related to the MedsCheck long-term care (Avery) and MedsCheck at Home (Abby). In addition, Avery Loi assisted with summarizing documentation changes and provided details related to long-term care homes in Ontario. Authors also thank Maha Chaudhry, Nancy He and Natalia Konstantelos for assistance during manuscript revisions.

Conflicts of Interest: The authors declare no conflict of interest.

\section{References}

1. Ministry of Health and Long-Term Care. Preventing and Managing Chronic Disease: Ontario's Framework; Queen's Printer for Ontario: Toronto, ON, Canada, 2007.

2. Institute of Medicine Committee on Identifying and Preventing Medication Errors. Preventing Medication Errors; National Academies Press: Washington, DC, USA, 2007.

3. Sichieri, K.; Rodrigues, A.R.B.; Takahashi, J.A.; Secoli, S.R.; Nobre, M.R.C.; Mónica, M.A.; Julio, F.G. Mortality associated with the use of inappropriate drugs according Beers criteria: A systematic review. Adv. Pharmacol. Pharm. 2013, 1, 74-84.

4. Dormann, H.; Criegee-Rieck, M.; Neubert, A.; Egger, T.; Geise, A.; Krebs, S.; Schneider, T.; Levy, M.; Hahn, E.; Brune, K. Lack of awareness of community-acquired adverse drug reactions upon hospital admission: Dimensions and consequences of a dilemma. Drug Saf. 2003, 26, 353-362. [CrossRef]

5. Tsuyuki, R.T.; Beahm, N.P.; Okada, H.; Al Hamarneh, Y.N. Pharmacists as accessible primary health care providers: Review of the evidence. Can. Pharm. J. 2018, 151, 4-5. [CrossRef] [PubMed]

6. Schnipper, J.L.; Kirwin, J.L.; Cotugno, M.C.; Wahlstrom, S.A.; Brown, B.A.; Tarvin, E.; Kachalia, A.; Horng, M.; Roy, C.L.; McKean, S.C.; et al. Role of pharmacist counseling in preventing adverse drug events after hospitalization. Arch. Intern. Med. 2006, 166, 565. [CrossRef] [PubMed]

7. Knudsen, P.; Herborg, H.; Mortensen, A.R.; Knudsen, M.; Hellebek, A. Preventing medication errors in community pharmacy: Frequency and seriousness of medication errors. Qual. Saf. Health Care 2007, 16, 291-296. [CrossRef] [PubMed]

8. Roberts, A.S.; Benrimoj, S.I.; Chen, T.F.; Williams, K.A.; Hopp, T.R.; Aslani, P. Understanding practice change in community pharmacy: A qualitative study in Australia. Res. Soc. Adm. Pharm. 2005, 1, 546-564. [CrossRef] [PubMed]

9. Houle, S.K.D.; Carter, C.A.; Tsuyuki, R.T.; Grindrod, K.A. Remunerated patient care services and injections by pharmacists: An international update. Can. Pharm. J. 2019, 152, 92-108. [CrossRef] [PubMed]

10. Latif, A.; Pollock, K.; Boardman, H.F. Medicines use reviews: A potential resource or lost opportunity for general practice? BMC Fam. Pract. 2013, 14, 57. [CrossRef] [PubMed]

11. Martin, D.; Miller, A.P.; Quesnel-Vallée, A.; Caron, N.R.; Vissandjée, B.; Marchildon, G.P. Canada's universal health-care system: Achieving its potential. Lancet 2018, 391, 1718-1735. [CrossRef]

12. Ontario Ministry of Health and Long-Term Care. The MedsCheck Program Guidebook, 2nd ed.; Queen's Printer for Ontario: Toronto, ON, Canada, 2008. 
13. Ontario Ministry of Health and Long-Term Care. Professional Pharmacy Services Guidebook, 3rd ed.; Queen's Printer for Ontario: Toronto, ON, Cananda, 2016.

14. MacCallum, L.; Consiglio, G.; MacKeigan, L.; Dolovich, L.; MacCallum, L. Uptake of community pharmacist-delivered MedsCheck diabetes medication review service in Ontario between 2010 and 2014. Can. J. Diabetes 2017, 41, 253-258. [CrossRef]

15. Government of Ontario. Central Forms Repository. Available online: http://www.forms.ssb.gov.on.ca/mbs/ ssb/forms/ssbforms.nsf?opendatabase\&ENV=WWE (accessed on 7 August 2019).

16. Canadian Council on Continuing Education in Pharmacy MedsCheck (Diabetes) Ontario. Available online: https://www.cccep.ca/pages/meds_check_diabetes_ontario.html (accessed on 17 May 2019).

17. Jandoc, R.; Burden, A.M.; Mamdani, M.; Lévesque, L.E.; Cadarette, S.M. Interrupted time series analysis in drug utilization research is increasing: Systematic review and recommendations. J. Clin. Epidemiol. 2015, 68, 950-956. [CrossRef] [PubMed]

18. Wagner, A.K.; Soumerai, S.B.; Zhang, F.; Ross-Degnan, D. Segmented regression analysis of interrupted time series studies in medication use research. J. Clin. Pharm. Ther. 2002, 27, 299-309. [CrossRef] [PubMed]

19. Bernal, J.L.; Cummins, S.; Gasparrini, A. Interrupted time series regression for the evaluation of public health interventions: A tutorial. Int. J. Epidemiol. 2016, 46, 348-355.

20. Lagarde, M. How to do (or not to do)... Assessing the impact of a policy change with routine longitudinal data. Health Policy Plan. 2012, 27, 76-83. [CrossRef] [PubMed]

21. Durbin, J.; Watson, G.S. Testing for serial correlation in least squares regression: I. Biometrika 1950, 37, 409-428. [PubMed]

22. Dickey, D.A.; Fuller, W.A. Distribution of the estimators for autoregressive time series with a unit root. J. Am. Stat. Assoc. 1979, 74, 427-431.

23. Zhang, F.; Wagner, A.K.; Soumerai, S.B.; Ross-Degnan, D. Methods for estimating confidence intervals in interrupted time series analyses of health interventions. J. Clin. Epidemiol. 2009, 62, 143-148. [CrossRef] [PubMed]

24. R Core Team. R: A Language and Environment for Statistical Computing; R Foundation for Statistical Computing: Vienna, Austria, 2013.

25. Dolovich, L.; Consiglio, G.; MacKeigan, L.; Abrahamyan, L.; Pechlivanoglou, P.; Rac, V.E.; Pojskic, N.; Bojarski, E.A.; Su, J.; Krahn, M.; et al. Uptake of the MedsCheck annual medication review service in Ontario community pharmacies between 2007 and 2013. Can. Pharm. J. 2016, 149, 293-302. [CrossRef]

26. Tracy, C.S.; Upshur, R.E.G. MedsCheck: An opportunity missed. CMAJ 2008, 178, 440. [CrossRef]

27. Pechlivanoglou, P.; Abrahamyan, L.; Mackeigan, L.; Consiglio, G.P.; Dolovich, L.; Li, P.; Cadarette, S.M.; Rac, V.E.; Shin, J.; Krahn, M. Factors affecting the delivery of community pharmacist-led medication reviews: Evidence from the MedsCheck annual service in Ontario. BMC Health Serv. Res. 2016, 16, 666. [CrossRef]

28. Ontario Public Drug Programs, Ministry of Health and Long-Term Care. Notice from the Executive Officer: MedsCheck Program Enhancements Standardization. Available online: http://www.health.gov.on.ca/en/pro/ programs/drugs/opdp_eo/notices/exec_office_20160704.pdf (accessed on 20 May 2019).

29. Ontario Pharmacists Association. MedsCheck Program. Available online: https://www.opatoday.com/ professional/resources/for-pharmacists/programs/medscheck (accessed on 2 July 2019).

30. Ontario Ministry of Health and Long-Term Care. MedsCheck Resources for Pharmacists-Health Care Professionals. Available online: http://www.health.gov.on.ca/en/pro/programs/drugs/medscheck/resources. aspx (accessed on 2 July 2019).

31. Ontario Ministry of Heath and Long-Term Care. Reforming Ontario's Drug System. Available online: https://news.ontario.ca/mohltc/en/2010/04/reforming-ontarios-drug-system.html (accessed on 29 May 2019).

32. Canadian Institute for Health Information; Canadian Patient Safety Institute; Institute for Safe Medication Practices Canada. Medication Reconciliation in Canada: Raising the Bar; Accreditiation Canada: Ottawa, ON, Canada, 2012.

33. Canadian Institute for Health Information. Prescribed Drug Spending in Canada, 2018: A Focus on Public Drug Programs; Accreditiation Canada: Ottawa, ON, Canada, 2018.

34. Strauss, M.; Howlett, K. Pharmacies Take Hit as Ontario Cuts Generic Drug Payments Again. Available online: https://www.theglobeandmail.com/globe-investor/pharmacies-take-hit-as-ontario-cuts-genericdrug-payments-again/article4170794/ (accessed on 29 May 2019). 
35. Ministry of Finance; Ministry of Heath and Long-Term Care. Stronger, Healthier Ontario Act (Budget Measures). 2017. Available online: https://news.ontario.ca/mof/en/2017/05/stronger-healthier-ontario-actbudget-measures-2017.html (accessed on 29 May 2019).

36. Barnes, B.; Hincapie, A.L.; Luder, H.; Kirby, J.; Frede, S.; Heaton, P.C. Appointment-based models: A comparison of three model designs in a large chain community pharmacy setting. J. Am. Pharm. Assoc. 2018, 58, 156-162. [CrossRef] [PubMed]

37. MacCallum, L.; Dolovich, L. Follow-up in community pharmacy should be routine, not extraordinary. Can. Pharm. J. 2018, 151, 79-81. [CrossRef] [PubMed]

38. Cipolle, R.J.; Strand, L.M.; Morley, P.C. Pharmaceutical Care Practice: The Patient-Centered Approach to Medication Management Services, 3rd ed.; McGraw-Hill Education: New York, NY, USA, 2012.

39. Ontario Ministry of Health and Long Term Care. MedsCheck at Home. Available online: http://www.health. gov.on.ca/en/pro/programs/drugs/medscheck/medscheck_home.aspx (accessed on 23 May 2019).

40. Ontario Long Term Care Association. This Is Long-Term Care 2018; Ontario Long Term Care Association: Toronto, ON, Canada, 2018.

41. Lipscombe, L.L.; Hux, J.E. Trends in diabetes prevalence, incidence, and mortality in Ontario, Canada 1995-2005: A population-based study. Lancet 2007, 369, 750-756. [CrossRef]

42. Statistics Canada Diabetes, by Age Group and Sex (Number of Persons). Available online: http://www. statcan.gc.ca/tables-tableaux/sum-som/101/cst01/health53a-eng.htm (accessed on 22 May 2018).

43. Ontario Ministry of Health and Long-Term Care. Diabetes: Strategies for Prevention. Available online: http://www.health.gov.on.ca/en/common/ministry/publications/reports/diabetes/diabetes.aspx (accessed on 22 May 2019).

44. Ontario Long Term Care Association. This Is Long-Term Care 2016; Ontario Long Term Care Association: Toronto, ON, Canada, 2016.

45. Craig, P.; Dieppe, P.; Macintyre, S.; Michie, S.; Nazareth, I.; Petticrew, M.; Medical Research Council guidance. Developing and evaluating complex interventions: The new Medical Research Council guidance. BMJ 2008, 337. [CrossRef] [PubMed]

46. Bleijenberg, N.; de Man-van Ginkel, J.M.; Trappenburg, J.C.A.; Ettema, R.G.A.; Sino, C.G.; Heim, N.; Hafsteindóttir, T.B.; Richards, D.A.; Schuurmans, M.J. Increasing value and reducing waste by optimizing the development of complex interventions: Enriching the development phase of the Medical Research Council (MRC) Framework. Int. J. Nurs. Stud. 2018, 79, 86-93. [CrossRef] [PubMed]

47. Drugs and Devices Division: Ministry of Health and Long-Term Care. Proposals to Establish More Efficient Pharmacy Reimbursement Policies. Available online: http://www.health.gov.on.ca/en/pro/programs/drugs/ opdp_eo/notices/exec_office_20190426.pdf (accessed on 2 July 2019).

48. Office of the Auditor General of Ontario. Chapter 3: Reports on Value-for-Money, 3.09: Ontario Public Drug Programs. 2017 Annual Report Volume 2; Queen's Printer for Ontario: Toronto, ON, Canada, 2017.

49. Ministry of Finance. 2019 Ontario Budget|Chapter 3: Ontario's Fiscal Plan and Outlook. Available online: http://budget.ontario.ca/2019/chapter-3.html (accessed on 2 July 2019).

50. Al-Rashed, S.A.; Wright, D.J.; Roebuck, N.; Sunter, W.; Chrystyn, H. The value of inpatient pharmaceutical counselling to elderly patients prior to discharge. Br. J. Clin. Pharmacol. 2002, 54, 657-664. [CrossRef] [PubMed]

51. Jack, B.W.; Chetty, V.K.; Anthony, D.; Greenwald, J.L.; Sanchez, G.M.; Johnson, A.E.; Forsythe, S.R.; O'Donnell, J.K.; Paasche-Orlow, M.K.; Manasseh, C.; et al. A reengineered hospital discharge program to decrease rehospitalization: A randomized trial. Ann. Intern. Med. 2009, 150, 178-187. [CrossRef] [PubMed]

52. Nazar, H.; Nazar, Z.; Portlock, J.; Todd, A.; Slight, S.P. A systematic review of the role of community pharmacies in improving the transition from secondary to primary care. Br. J. Clin. Pharmacol. 2015, 80, 936-948. [CrossRef] [PubMed]

53. Ali, M.; Schifano, F.; Robinson, P.; Phillips, G.; Doherty, L.; Melnick, P.; Laming, L.; Sinclair, A.; Dhillon, S. Impact of community pharmacy diabetes monitoring and education programme on diabetes management: A randomized controlled study. Diabet. Med. 2012, 29, e326-e333. [CrossRef] [PubMed]

54. Krass, I.; Armour, C.L.; Mitchell, B.; Brillant, M.; Dienaar, R.; Hughes, J.; Lau, P.; Peterson, G.; Stewart, K.; Taylor, S.; et al. The Pharmacy diabetes care program: Assessment of a community pharmacy diabetes service model in Australia. Diabet. Med. 2007, 24, 677-683. [CrossRef] 
55. Al Hamarneh, Y.N.; Charrois, T.; Lewanczuk, R.; Tsuyuki, R.T. Pharmacist intervention for glycaemic control in the community (the RxING study). BMJ Open 2013, 3, e003154. [CrossRef]

56. Kallio, S.E.; Kiiski, A.; Airaksinen, M.S.A.; Mäntylä, A.T.; Kumpusalo-Vauhkonen, A.E.J.; Järvensivu, T.P.; Pohjanoksa-Mäntylä, M.K. Community pharmacists' contribution to medication reviews for older adults: A systematic review. J. Am. Geriatr. Soc. 2018, 66, 1613-1620. [CrossRef]

57. Jokanovic, N.; Tan, E.C.; Sudhakaran, S.; Kirkpatrick, C.M.; Dooley, M.J.; Ryan-Atwood, T.E.; Bell, J.S. Pharmacist-led medication review in community settings: An overview of systematic reviews. Res. Soc. Adm. Pharm. 2017, 13, 661-685. [CrossRef]

(C) 2019 by the authors. Licensee MDPI, Basel, Switzerland. This article is an open access article distributed under the terms and conditions of the Creative Commons Attribution (CC BY) license (http://creativecommons.org/licenses/by/4.0/). 